NBER WORKING PAPER SERIES

PRIVATE COST INFORMATION

$\triangle$ ND THE MULTINATIONAL ENTERPRISE

Kyle Bagwell

Robert W. Staiger

Working Paper No. 2657

NATIONAL BUREAU OF ECONOMIC RESEARCH

1050 Massachusetts Avenue

Cambridge, MA 02138

July 1988

This paper has benefitted from the comments of Thomas Prusa, Michael Riordan, and members of the International Seminar at Harvard University. This research is part of NBER's research program in International Studies. Any opinions expressed are those of the authors not those of the National Bureau of Economic Research. 
NBER Working Paper \#2657

July 1988

\section{PRIVATE COST INFORMATION \\ AND THE MULTINATIONAL ENTERPRISE}

\section{ABSTRACT}

This paper explores the informational role of plant location decisions for the multinational enterprise. When information about costs is incomplete, the location of a plant will be chosen not only for its impact on actual production costs, but also for its impact on the perception of costs as held by foreign rivals. We show that the latter consideration, which can arise only in the presence of asymmetric information about costs, may lead to a decision to multinationalize even though actual production costs are higher as a result. As such, the informational role of plant location decisions is a potentially important element in understanding the behavior of the multinational firm.

Kyle Bagwell

Department of Economics Northwestern University

Evanston, IL 60208
Robert W. Staiger

Department of Economics

Stanford University

Stanford, CA 94305 


\section{Introduction}

The multinational $\mathrm{firm}$ is generally thought to arise as a result of three ingredients. - A firm must first possess an ownership advantage (patent, expertise, etc.) which it wishes to exploit in foreign markets. Second, locational considerations (tariffs, transport costs, etc.) must dictate that supplying foreign markets is best acnieved with foreign production. Finally, the firm must choose internalization over an arms-length transaction $(e . g .$, open its own plant abroad ratiner tinan licensing its tecinology).

Ethier (1986) has argued that the internalization decision is the least well-understood of these three ingredients, and that the decision between internalization and arms-length transactions is largely an issue of the international economics of information. As such, to understand the internalization decision, one must analyze the exchange of information between agents.

We argue in this paper that the analysis of information exchange between agents is also important in understanding the location decision. In particular, when there exists strategic interaction between the firms of different countries serving a foreign market, the transmission of information about production costs becomes crucial. ?' If the location of production facilities in the foreign market can serve to directly inform rival firms of an entrant's production costs, or if the decision to locate production facilities there signals the costs of the entrant, then multinationalization can arise as a way of transmitting cost information to foreign rivals. Consequently, in the presence of 
asymetric information about costs, the role of locational

considerations takes on a new dimension. In this paper, we explore this new dimension of the foreign locational decision.

Specifically we show that, when cost information is incomplete among rival firms for a foreign market, the choice of plant location will potentially have two effects on 3 firm's profits: it will effect the firm's actual production costs to the extent that factor-price differentials exist between countries, and it may effect the perception of the firm's production costs as held by rival firms. While the former effect leads plants to locate where actual costs are lowest, the latter effect need not. Taking the two effects together, a firm may be led to multinationalize even though its actual costs of serving the foreign market are higher as a result. Such multinational equilibria, which arise solely as a result of incomplete information about costs, are the focus of this paper.

We are certainly not the first to point out the informational dimensions of a firm's location decision. This idea was central to the notion of a product cycle as developed by Vernon (1966). Vernon argued, for example, that in the early stages of supplying a new market, ...the need for swift and effective communication on the part of the producer with consumers, suppliers, and even competitors is especially high at this stage. This is a corollary of the fact that a considerable amount of uncertainty remains regarding the ultimate dimensions of the market, the efforts of rivals to preempt that market, the specifications of the inputs needed for 
production, and the specifications of the products likely to te most successful in the effort. (p. 195)

Vernon concludes that such informational demands are one reason why a firm would wish to locate in the market it is about to serve. However, the relationship tetween location and communication is not analyzed: it is simply taken as given that locational proximity and effective communication go hand in hand. The work that we present below can be viewed as an attempt to formalize one aspect of the relationsinip between location and information exchange.

The remainder of the paper proceeds as follows. Section II lays out the general model and derives necessary and sufficient conditions for multinationalization to take place solely as a result of the desire to transmit cost information to foreign rivals. Section II then explores several specific cases in which the general conditions derived in section II are met. Section IV concludes.

\section{The Game and General Properties}

Our ideas are most easily expressed in a general setting. We therefore provide in this section a characterization of the game in terms of general reduced-form profit functions. In later sections, we evaluate these functions under specific assumptions about demand and cost conditions.

Consider two countries, one (the foreign country) with a new market for a good in which the entry decisions of $\mathrm{N}-1$ forelgn firms (labeled $\mathrm{j}=1,2, \ldots, N-1$ ) are just being made, and the other (the home 
country) with a single established domestio firm (labeled $N$ ) who serves the home market and is currently considering entry into the foreign market as well. For simplicity, we assume constant cost technologies, that entry is pronibited in the domestic narket, and tinat there exists a pronititive tariff on imports of the good into the nome country as well, so that the domestio firm can make its entry decision into the foreign market without regard to the domestic market.

With regard to the (new) foreign market, all relevant demand information is assumed to te common knowledge to the $\mathrm{N}$ firms. In addition, all relevant information concerning the production costs of the $\mathrm{N}-1$ foreign firms is assumed to be common knowledge among all $\mathrm{N}$ firms. For simplicity, we assume that variable costs of the $\mathrm{N}-1$ foreign firms are identical, and that they take the form of a wage $w^{*}$ times a unit labor requirement $\alpha$. However, the domestio firm has production costs which, at least initially, are known to it alone. The source of this one-sided informational asymmetry can be either firmspecific or country-specific. 3 ' we consider each case in turn.

In the case of firm-specific one-sided asymmetrlc information, we assume that prevailing wages at home and abroad differ but are common knowledge to all $N$ firms, that the domestic wage $W$ is less than the foreign wage $w^{*}$, and that the $N^{-1}$ foreign firms use a commonly known technology a. However, the domestic firm has available to it a new technology with unit labor requirements $\theta$ known to it alone. The domestic firm must now decide whether to "stay" (produce its export good domestically, facing the commonly known (low) domestic wage $w$ ) or to 
"go" (open a plant abroad and operate its technology in the presenoe of the commonly known (nigh) foreign wage $\left.w^{*}.\right)^{4}$ The latter option corresponds to the choice of multinationalization. Once the domestic firm has made its (observable) location decision, the $N$ firms engage in Cournot quantity competition for the foreign market, with the sequence of play represented grapinically in Figure $1 . \underline{5}$

In the case of country-specific one-sided asymmetric information, we assume that all $N$ firms employ the same commonly known technology $\alpha$, and that the $N-1$ foreign firms face a wage $w^{*}$ that is assumed to be common knowledge to all $\mathrm{N}$ firms. However, the domestic firm alone knows the wage of labor in the home country, w. It must now decide whether to produce its export good in the domestic plant or to multinationalize and open a new plant in the foreign country. If the domestic firm decides to "stay" in the domestic country, then it retains some private information about its labor costs, wa, through its private knowledge about $w$. But, if the firm chooses to "go" and build a foreign plant, the $N$ firms all face the commonly known forelgn wage $w^{*}$, and their unit labor costs $w^{*} \alpha$ are then common knowledge and identical. In the latter case, we allow for the possibility that a portion of any plant-specific flxed costs of operating a forelgn plant, e.8., accounting, are carrled out by the home operations, and thus reflect in part the domestic wage $w$ : however, since these are fixed costs, they w11l affect directly the multinational's profits but not its strategic interaction with rival firms. 
Thus, by staying home, the domestic firm pays the domestic wage and faces foreign rivals that are not completely informed about that wage, while by going to the foreign country, the domestio firm fices the well-known foreign wage: the location choice in this case is a choice of information structure for the ensuing oligopolistic rivalry. As before, once the domestio firm has made its (observable) location choice, the $N$ firms engage in Cournot quantity competition for the foreign market. The sequence of play is represented graphically in Figure 1 .

Notice that in both the firm-specific and the country-specific case, the domestic firm's choice of location is important in two respects. First, the choice determines the firm's actual costs. Second, foreign firms may (rationally) use the location decision of the domestic firm as a signal of its cost type, as certain cost types may be more willing to stay than others. Since the output choices of the N1 foreign firms depend on their expectation of the domestic firm's output selection, and since the domestic firm's output selection depends on its costs, the quantity of output of foreign firms depends on their perception of the domestic firm's costs. Thus, in making its choice of location, the domestic firm must also consider the affect that its location decision would have on its percelved production costs.

We now give a formal representation of the general game. The first player to move is "nature," who chooses the unknown cost parameter ( $\theta$ In the firm-specific case and $w$ in the country-specific case). It Is commonly known among all players that nature chooses a high cost 
parameter with probability $\delta_{\mathrm{H}} \in(0,1)$ and a low cost parameter with probability $1-\delta_{\mathrm{H}}$. The domestic $\mathrm{firm}$ is then privately informed about the realized cost parameter, and chooses a plant location. Letting $c=\{L, H\}$ and $z=\{S, G\}$ represent, respectively, the set of possible cost parameters ( $L=$ low, $H=h i g h)$ and the set of possible plant locations ( $\equiv$ stay, $G \equiv$ go) for the domestic firm, we represent the tomestic firm's location strategy as a mapping $z: c \rightarrow z$.

Consider first the firm-specific case. After observing the domestic firm's location choice, forelgn firms must posit some belief about the domestic firm's type. Let $\hat{b}(z) \varepsilon[0,1]$ represent the probability with which the $\mathrm{N}-1$ foreign flrms believe the domestic firm to have high unit labor requirements after observing the firm's location decision $z$. We then define $\Pi^{N}\left(w(z) \theta^{i} \mid \hat{b}(z)\right)-F^{N}(i, z)$, with $i=H$ or $L, w(z=S)=w, w(z=G)=w^{*}$, and $F^{N}(i, z=S)=0$, as the total profit to the domestic firm if its technology is actually of type i but it is perceived to have high unit labor requirements with probability $\hat{b}(z)$ when its location decision is $z$. $/$ Finally, define $\left.\pi^{j} \hat{b}(z), z\right)-F^{j}$ as the expected total profit to foreign firm $j=1, \ldots, N-1$ when the domestic firm's location cholce is $z$ and its unit labor requirements are perceived to be high with probability $\hat{b}(z)$. $\Pi^{N}\left(w(z) \theta^{i} \mid \hat{b}(z)\right)-F^{N}(i, z)$ and $\Pi^{j}(\hat{b}(z), z)-F^{j}$ thus summarize the payofis associated with the firm-specific one-sided incomplete information Cournot game in which the high cost technology is believed to occur with probability $\hat{b}(z)$. 
Consider alternatively the country-specific case. If the domestic firm chooses to go, then aII $N$ firms have medium (M) costs, and the firms play a complete information cournot game. We let $\Pi_{M}^{j}$ represent the variatle profits to the $j$ th firm in this game, with $j=1,2, \ldots, N$. Set-up costs in the foreign country for foreign firms $j=1,2, \ldots, N-1$ and for the domestio firm $N$ facing domestio wages of type $i$ will be denoted by $E^{j}$ and $F^{N}(i), i=H, L$, respectively.

If instead the domestic firm chooses to stay, then the foreign firms must posit some belief about the domestio firm's type. Let $\hat{b} \in[0,1]$ represent the probability with which the $N-1$ foreign firms believe the domestic firm to face nigh wages after observing that the firm has decided to stay. We can then define $\pi^{N}\left(w^{i} \alpha \mid \hat{b}\right)$, where $i=H$ or $L$, to be the total profit to the domestic firm when it produces domestically, actually faces a wage of type $i$, and is perceived to face a nigh wage with probability $\hat{b}$ (the decision to stay eliminates the need for additional plant-specific set-up costs). Likewise, we can define $\Pi^{j}(\hat{b})$ to be the expected variable profit to foreign firms $j=1,2, \ldots, N-1$ facing a domestically-located $N$ th firm that is thought to pay the high wage with probability $\hat{b} \cdot \Pi^{N}\left(w^{i} \alpha \mid \hat{b}\right)$ and $\Pi^{j}(\hat{b})-F^{j}$ thus summarize the payofs associated with the country-specific one-sided incomplete information Cournot game in which high wages are believed to occur with probability $\hat{b}$.

We look for a sequential equilibrlum (Kreps-Wilson (1982)). In the present game, a sequential equilibrium is simply a combination of strategies and beliefs such that 1) strategies are sequentially 
rational, in that each player's strategy maximizes his expected payof given his beliefs and the strategies of his opponents, and 2) beliefs are Bayes-consistent, in that they agree with Bayes' Rule along the equilibrium path (i.e., for events that occur with positive probability in the equiliorium). The application of sequential rationality to the quantity games is implicit in the definitions of the profit functions above. I' The domestic firm's location strategy is sequentially rational, if, given the structure of beliefs, the firm with cost parameter i chooses the location corresponding to the maximum of the set $\left\{\pi^{N}\left(w^{*} \theta^{\hat{L}} \mid \hat{b}(z=G)\right)-E^{N}(i, z=G), \Pi^{N}\left(w \theta^{i} \mid \hat{b}(z=S)\right)\right\}$ in the firm-specific case, and $\left\{\Pi_{M}^{N}-F^{N}(i), \Pi^{N}\left(w^{i} \alpha \mid \hat{b}\right)\right\}$ in the country-specific case. For example, if $\pi^{N}\left(w_{\alpha}^{L} \mid \hat{b}\right)$ and $\pi^{N}\left(w_{\alpha}^{H} \mid \hat{b}\right)$ exceed $\pi_{M}^{N}-F^{N}(L)$ and $\pi_{M}^{N}-F^{N}(H)$, respectively, then sequential rationality requires $z(L)=$ $z(H)=S$ in the country-specific game. Finally, Bayes-consistency is met if and only if the following conditions nold:

\section{Firm-Specific Case}

(i) If $z(L)=z(H)=k$, then $\hat{b}(z=k)=\delta_{H}$ for $k=\{S, G\}$. (11) If $z(L) * z(H)=S$, then $\hat{b}(z=S)=1$ and $\hat{b}(z=G)=0$. (111) If $z(H) * z(L)=S$, then $\hat{b}(z=S)=0$ and $\hat{b}(z=G)=1$.

\section{Country-Specif ic Case}

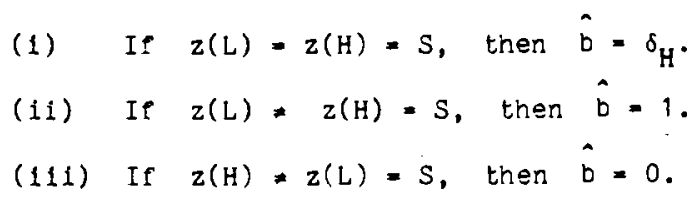


In case i), pooling occurs in that the location choice provides no information about cost type. Bayesian updating then requires the posterior belief $(\hat{b})$ to equal the prior belief $\left(\delta_{H}\right)$. By contrast, in cases ii) and iii), location choices separate firm types. Here, Bayesian updating requires foreign firms to correctly guess the domestio firm's type. Otserve finally that $\hat{b}$ is unrestricted when $z(L)=$ $z(H)=G$ in the country-specific case, for in this case the $S$ choice is a zero probability event ("off the equilibrium path") and so Bayes' Rule can not te applied. Likewise, in the firm-specific case, $\hat{b}(z=G)$ is unrestricted when $z(L)=z(H)=S$, and $\hat{b}(z=S)$ is unrestricted when $z(L)=z(H)=G$. We discuss these possibilities in more detail below.

Having defined a sequential equilibrium for our game, we now place assumptions on the profit functions and then explore the nature of equilibrlum behavior. We consider each case in turn.

\section{Firm-Specific Case}

\section{Assumptions}

(1) $\Pi^{N}\left(w(z) \theta^{1} \mid \hat{b}\right)$ is strictly decreasing in $\hat{b}$ for all $1 \in\{L, H\}, \hat{b} \in[0,1], z \in\{S, G\}$.

(11) $\Pi^{N}\left(w(z) \theta^{L} \mid \hat{b}\right)>\Pi^{N}\left(w(z) \theta^{H} \mid \hat{b}\right)$ for aII $\hat{b} \in[0,1], z \in\{S, G\}$.

(iii) $\Pi^{N}\left(w \theta^{i} \mid \hat{b}\right)>\Pi^{N}\left(w^{*} \theta^{i} \mid \hat{b}\right)-F^{N}(i, z=G)>0$ for all $\hat{b} \in[0,1]$ and $i \varepsilon\{L, H\}$.

(iv) $\Pi^{j}(\hat{b}, z)-F^{j}$ is nonnegative for all b $\varepsilon[0,1], j \in[1,2, \ldots, N-1\}, z \in\{S, G\}$. 
The interpretation of assumptions (i) tinrough (iv) is as

follows. Assumption (i) says that the domestic firm earns higiner profits the more likely it is held by rival firms to have low unit labor requirements (regardless of its actual technology). Assumption (ii) represents the actual savings asjociated with low unit labor requirements. Assumption (iii) says that, given any belief $\hat{b}$, botn firm types would rather locate at home than abroad, but that profits are positive at either location. In particular, with complete information, neither firm type would choose to multinatinalize. Finally (iv) guarantees that each of the foreign firms earn nonnegative profits. As we will show, these assumptions are consistent with Cournot competition under the assumption that $w^{*}>w$.

According to assumption (iii), full information would have neither firm type multinationalize in the firm-specific case. We focus in the firm-specific case on multinational equilibria in which, as a result of the flrm-specific informational asymmetry, one or both firm types 80 . The first theorem concerns the case in which the domestlo firm chooses to multinationalize regardless of its type. We call such equilibria pooling multinational equilioria.

Theorem 1: A pooling multinational equilibrium exists if and only if

$$
\pi^{N}\left(w^{*} \theta^{i} \mid \delta_{H}\right)-F^{N}(i, z=G) \geq \pi^{N}\left(w \theta^{i} \mid 1\right), \quad i=H, L
$$


Proof: Suppose first that an equilibrium exists with $z(\mathrm{~L})=z(\mathrm{H})=$ G. Then Bayes-consistency requires that $\hat{b}(z=G)=\delta_{H}$. Therefore, $\Pi^{N}\left(w^{*} \theta^{i} \mid \delta_{H}\right)-F^{N}(1, z=G) \geq \Pi^{N}\left(w \theta^{i} \mid \hat{b}(z=S)\right) \geq \Pi^{N}\left(w \theta^{i} \mid 1\right)$ is recessary for $i=H$ and $L$, since otherwise $z(i)=S$ would be selected for $i=H$ or $L$ instead. Coing the other way, suppose $\pi^{N}\left(w^{*} \Theta^{i} \mid \delta_{H}\right)-F^{N}(i, z=G) \geq \pi^{N}\left(w^{i} \mid 1\right), i=H, L$. Put $z(L)=z(H)=G$ and $\hat{b}(z=S)=1$. Then, since $\pi^{N}\left(w^{*} \theta^{i} \mid \delta_{H}\right)-F^{N}(i, z=G) \geq \pi^{N}\left(w \theta^{i} \mid 1\right)$ for $i=H$ and $L$, the location choice is sequentlally rational. Q.E.D.

The pooling multinational equilibrium constructed in the proof of Theorem 1 is supported by the pessimistic belief that if the domestio firm is observed to stay then it must have high unit labor requirements. Our equilibrium conoept imposes no restrictions on $\hat{b}(z=S)$ when equilibrium has $z(L)=z(H)=G$, i.e., in the pooling multinational equilibrium, but it is nonetheless important to ask whether $\hat{b}(z=S)=1$ is a plausible belief specification in this case. This belief specification would be plausible if the high unit labor requirement elrm were thought to be more likely to deviate from the pooling multinational equilibrlum than the low unit labor requirement firm. But in fact given the prior belief $\delta_{H}$ both have an incentive to deviate and stay in the domestic country. Hence, there is a strong sense in which the "credible" belief is $\hat{b}(z=S)=\delta_{H}$. But pooling multinational equilibrla will not exist if $\hat{b}(z=S)=\delta_{H}$, since $\pi^{N}\left(w \theta^{1} \mid \delta_{H}\right)>\pi^{N}\left(w^{*} \theta^{1} \mid \delta_{H}\right)-F^{N}(1, z=G)$ for $1 \in\{L, H\}$ according to assumption (iii). 
With the above argument in mind, we follow Grossman and Perry (1986) and refer to pooling equilibrla that are immune to such logic as credible pooling multinational equilibria. The next theorem is then immediate.

Theorem 2: Credible pooling multinational equilibria do not exist.

We turn next to separating equiliorla. The following theorem states conditions under which separating mult inational equilioria exist with $z(H)=z(L)=G . \underline{8}$

Theorem 3: A separating multinational equllibrlum exists with $z(H) * z(L)=G$ if and only if $\pi^{N}\left(w^{H} \mid 1\right) \geq \pi^{N}\left(w^{*} \theta^{H} \mid O\right)-F^{N}(H, G)$ and $\Pi^{N}\left(w^{*} \theta^{L} \mid 0\right)-F^{N}(L, G) \geq \pi^{N}\left(w^{L} \mid 1\right)$.

Proof: Suppose a separating equilibrium exists with $z(H) \neq z(L)=G$. Then $\pi^{N}\left(w \theta^{H} \mid 1\right) \geq \pi^{N}\left(w^{*} \theta^{H} \mid 0\right)-F^{N}(H, G)$ since otherwise $H$ would deviate and go, while $\pi^{N}\left(w^{*} \theta^{L} \mid O\right)-F^{N}(L, G) \geq \pi^{N}\left(w^{L} \mid 1\right)$ since otherwise $L$ would deviate and stay. Going the other way, suppose that $\Pi^{N}\left(w \theta^{H} \mid 1\right) \geq \Pi^{N}\left(w^{*} \theta^{H} \mid 0\right)-F^{N}(H, G)$ and $\Pi^{N}\left(w^{*} \theta^{L} \mid 0\right)-F^{N}(L, G) \geq \pi^{N}\left(w \theta^{L} \mid 1\right)$. Then the location cholce $z(H)=z(L)=G$ is sequentially rational, given the Bayesian beliefs that must follow. Q.E.D. When the conditions of Theorem 3 are satisfied, the domestic firm's decision of whether to export to the foreign market or to multinationalize depends on whether 1 ts technology has high or low unit labor requirements. In particular, even though both firm types will 
have lower actual costs if the good is produced domesticaliy and exported to the foreign market, a firm with low unit labor requirements may choose to locate production in the high wage foreign market in order to signal to its rivals that its unit labor requirements are indeed low. 9 '

Finally, we define a notion of undominated equilibria and give conditions under which the separating equilibrium is unique within this class. A locational choice $z$ is said to be dominated for a firm of type $i$ if the firm makes less with the choice of $z$ under the best of situations $(\hat{b}(z)=0)$ than it makes with the alternative cholce $z$ ' under the worst of conditions $\left(\hat{b}\left(z^{\prime}\right)=1\right)$. Clearly, a dominated strategy will never be played. As Kohlberg and Mertens (1986) and Milgrom and Roberts (1986) have argued, it seems therefore reasonable to require that foreign firms never believe that a dominated strategy had been played. Equilibria which satisfy this plausibility restriction on beliefs are then referred to as undominated equilibria. With this definition in place, we now give conditions under which "going" is dominated for the high unit labor requirement firm and profitable to the low unit requirement firm if $\hat{b}(z=G)=0$. The unique undominated equilibrium must then be the separating multinational equilitrium. Theorem 4: Suppose that $\pi^{N}\left(w^{H} \mid 1\right)>\pi^{N}\left(w^{*} \theta^{H} \mid 0\right)-F^{N}(H, G)$ and that $\pi^{N}\left(w^{*} \theta^{L} \mid 0\right)-F^{N}(L, G)>\pi^{N}\left(w \theta^{L} \mid \delta_{H}\right)$. Then there exists an unique undominated equilibrium, in which $z(H) \neq z(L)=G$ : that is, the unique undominated equilibrium is the separating multinational equilibrium. 
Proof: We show first that $z(H) \neq z(L)=G$ in any undominated equilibrium. Observe that $z(H)=G$ is tominated for $H$, since $\pi^{N}\left(w \theta^{H} \mid 1\right)>\pi^{N}\left(w^{*} \theta^{H} \mid 0\right)-F^{N}(H, G)$. Thus, $z(H)=S$ and $\hat{b}(z=G)=0$ must be true in an undominated equilibrium. Now, $z(L)=z(H)=S$ is then impossible, since $\pi^{N}\left(w^{*} \theta^{L} \mid 0\right)-E^{N}(L, G)>\pi^{N}\left(w \theta \mid \delta_{H}\right)$. It must therefore be that $z(L) \neq z(H)=S$. Next, we complete the proof by noting that the separating multinational equilibria is in fact undominated and (by Theorem 3) does exist under the conditions of Theorem 4. Q.E.D.

The first condition of Theorem 4 is more likely to be met the greater is the foreign-domestic wage differential and the greater is $\theta^{\mathrm{H}}$. The second condition is more likely to nold the smaller the wage differential and the smaller is $\theta^{L}$. Intuitively, then, the separating multinational equilibrium should be the unique undominated equilibrium provided that the efficiency differential is large but that the wage differential is not too extreme. This intuition is borne out in the linear demand example we explore in the following section.

\section{Country-Specific Case}

\section{Assumptions}

(i) $\pi^{N}\left(w^{1} \alpha \mid \hat{b}\right)$ is strictly jecreasing in $\hat{b}$, for all $i \in[L, H\}, \hat{b} \in[0,1]$.

(ii) $\pi^{N}\left(w_{\alpha}^{L} \mid \hat{b}\right)>\pi^{N}\left(w^{H} \alpha \mid \hat{b}\right)$ for all $\hat{b} \in[0, i]$.

(iii) $\pi^{N}\left(w_{\alpha}^{L} \mid 0\right)>\pi_{M}^{N}-F^{N}(L) \geq \pi_{M}^{N}-F^{N}(H)>\pi^{N}\left(w_{\alpha}^{H} \mid 1\right)>0$. 


$$
\text { (iv) } \begin{aligned}
& \Pi_{M}^{j}-F^{j} \text { and } \Pi^{j}(\hat{b})-F^{j} \text { are non negative for all } \\
& \hat{b} \varepsilon[0,1] \text { and } j=1,2, \ldots, N-1 \text {. }
\end{aligned}
$$

The assumptions are simple to interpret. By (i), the domestio firm earns higher profits when it locates domestically the more likely it is neld by rival firms to face low domestic wages (regardless of the actual domestic wage). Assumption (ii) represents the actual savings associated with a low wage while (iii) ensures that complete information variable profits are always greater than fixed costs for the domestic firm, and that with complete information and facing a high (low) wage at home the domestic firm would choose (not) to multinationalize. Finally, (iv) guarantees that foreign firms make non-negative profit. As we will see, these assumptions are consistent with Cournot competition when $w^{H}>w^{*}>w^{L}$.

Given assumption ( $i$ ii), complete information would have the domestic firm export if it faces the low wage at home and multinationalize if the home wage is high. Our primary interest in the country-specific case is on equilioria in which multinationalization occurs, regardless of the domestic wage; that is, we wish to focus on equilibria in which $z(L)=z(H)=G$. We refer to such equilibria as multinational equilioria.

Theorem 5: A multinational equiliorium exists if and only if $\pi_{M}^{N}-F^{N}(1) \geq \pi^{N}\left(w^{i} \alpha \mid 1\right), 1=H, L$. 
Proof: Suppose first that an equilibrium exists in which $z(L)=z(H)=G$. Then $\pi_{M}^{N}-F^{N}(i) \geq \pi^{N}\left(w^{i} \alpha \mid \hat{b}\right) \geq \pi^{N}\left(w^{i} \alpha \mid 1\right)$ is necessary for $i=H$ and $L$, lest $z(1)=S$ be selected for $i=H$ or $L$ instead. Going the other way, suppose $\pi_{M}^{N}-F^{N}(1) \geq \pi^{N}\left(w^{i} \alpha \mid 1\right), 1=H, L$. Put $z(L)=z(H)=G$ and $\hat{b}=1$. Then, since $\pi_{M}^{N}-F^{N}(i) \geq \pi^{N}\left(w^{i} \alpha, 1\right)$ for $i=H$ and $L$, the location choices are sequentially rational. Q.E.D.

As in the pooling multinational equillorium of Theorem 1, the multinational equilibrium constructed in the proof of Theorem 5 is supported by the pessimistic belief that if the domestic firm stays then it faces high wages. Our equilibrium concept imposes no restrictions on $\hat{b}$ in multinational equilibria, and it is thus important to ask whether $\hat{b}=1$ is a plausible belief speciflcation. In one case it certainly is not. Specifically, suppose that $\pi_{M}^{N}-F^{N}(i) \geq \pi^{N}\left(w^{i} \alpha \mid 1\right)$ for $i=H, L$, and $\Pi_{M}^{N}-F^{N}(H)>\pi^{N}\left(w^{H} a \mid 0\right)$; that is, suppose that a multinational equilibrium exists and that facing high domestic wages, the domestic firm would rather go than stay, even if in staying it faced the "best" beliefs $(\hat{b}=0)$. In this case, $z(H)=S$ is dominated by $z(H)=G$ in the presence of $h i g h$ domestic wages. Since $\pi^{N}\left(w_{\alpha}^{L} \mid 0\right)>\pi_{M}^{N}-F^{N}(L)$ by assumption (111), there are beliefs which might make $z(L)=S$ the optimal cholce for the domestic firm when it faces low domestic wages. Thus, since staying is tominated by going for the domestic firm when domestic wages are hlgh but not when they are low, tre only reasonable belief is $\hat{b}=0$. But this belief could not support the multinational equilibrium, as it would induce the domestic firm to stay if it faced low domestic wages. When $\pi_{M}^{N}-F^{N}(H)>\Pi^{N}\left(w^{H} \mid 0\right)$, multinat lonal 
equilibria and thus implausible equilitria. Referring again to multinational equilibria that are immune to such logic as undominated multinational equilibria, we now have the following theorem.

Theorem 6: An undominated multinational equilibrium exists if and only if $\pi^{N}\left(w^{H} \alpha \mid 0\right) \geq \Pi_{M}^{N}-E^{N}(H) \geq \pi^{N}\left(w^{H} \alpha \mid 1\right)$ and $\Pi_{M}^{N}-E^{N}(L) \geq \Pi\left(w^{L} \alpha \mid 1\right)$.

In words, multinationalization is plausible in the countryspecific case if and only if the domestio firm does better when it stays, actually faces high wages, and is perceived to face a low wage than when it multinationalizes; and does better when it multinationalizes than when it stays and is thought to face inigh wages, regardless of its actual wage. Thus, multinationalization seems most likely in the country-speciflo case when perceived costs have a greater affect on profits tinan do actual costs. One would thus expect multinationalization to occur if foreign output is very sensitive to perceived domestic costs.

The multinational equilibrium is inefficient, relative to a complete information setting, in that it entails too much multinationalization. Speciflcally, the domestic firm bullds a forelgn plant even if the foreign wage is higher than the domestic wage. When the choice of location is a potential signal, it is simply not true that firms necessarily locate production facilities where costs are lowest. Notice nowever, that when the domestic wage is high, the domestic firm does receive an actual cost savings by multinationalizing. 
We now give conditions under which the multinational equilitr fum is unique.

Tneorem 7: Suppose that $\Pi_{M}^{N}-F^{N}(L)>\Pi^{N}\left(w_{\alpha}^{L} \mid 1\right)$ and $\Pi^{N}\left(w^{H} \alpha \mid 0\right)>\pi_{M}^{N}-F^{N}(H)>\Pi^{N}\left(w^{H} \alpha \mid \delta_{H}\right)$. Then, in any equilibrlum, $z(L)=$ $z(H)=G$; that is, every equilibrium is a multinational equilibrium. Moreover, the multinational equilitrium exists and is undominated.

Proof: Existence and dominance arguments follow directly from Theorem 6. We prove here that every equilibrium is a multirational equilibria. The proof is by contradiction. Consider first the possibility that $z(L)=z(H)=S$. Then $\hat{b}=\delta_{H}$ and so the domestic firm facing domestic wages of type $i$ earns $\pi^{N}\left(w^{i} \alpha \mid \delta_{H}\right)$. But $\Pi_{M}^{N}-F^{N}(H)>\Pi^{N}\left(w_{\alpha}^{H} \mid \delta_{H}\right)$, so $z(H)=S$ is not sequentialiy rational. Consider second $z(L)=z(H)=S$. Then $\hat{b}=1$. This is contradictory, nowever, since $\Pi_{M}^{N}-F^{N}(H)>\pi^{N}\left(w^{H} \alpha \mid \delta_{H}\right)>\Pi^{N}\left(w^{H} \alpha \mid 1\right)$. Finally, consider $z(H)=z(L)=S$. Then $\hat{b}=0$. But $z(H)=G$ is then suboptimal, since $\Pi^{N}\left(w_{\alpha}^{H} \mid 0\right)>\pi_{M}^{N}-F^{N}(H)$. The only remaining case is $z(L)=z(H)=G$. Q.E.D. Notice that $\pi^{N}\left(w_{\alpha}^{H} \mid \delta_{H}\right)<\Pi_{M}^{N}-F^{N}(H)$ certainly holds by assumption (111) if $\delta_{\mathrm{H}}$ is near one and, in general, is more likely to hold the higher is $\delta_{H^{*}}$. Thus, if the domestic wage is likely to be high (1.e., $\left.\pi^{N}\left(w_{\alpha}^{H} \mid \delta_{H}\right)<\pi_{M}^{N}-F^{N}(H)\right)$, and if perceptual cost effects are strong (1.e.. $\Pi^{N}\left(w_{\alpha}^{H} \mid 0\right)>\Pi_{M}^{N}-F^{N}(H)$ and $\left.\Pi_{M}^{N}-F^{N}(L)>\Pi^{N}\left(w_{\alpha}^{L} \mid 1\right)\right)$, then the undominated multinational equilitrium is the unique equiliorium. 
Before concluding this section, we briefly discuss the possibility of other equilibria in the country-specific case. There exist equilibria in which the domestic firm stays regardiess of the domestio wage type $(z(L)=z(H)=S)$ if and only if $\pi^{N}\left(w^{i} \alpha \mid \delta_{H}\right) \geq \pi_{M}^{N}-E^{N}(i) i=H, L$. (The proof is straightforward.) Thus, if $\delta_{\mathrm{H}}$ is small, it may be that too little multinationalization occurs, relative to complete information choices. There may also exist efficient equilibria, that is, equilibria in which $z(H)=z(L)=S$. Efficient equilibria are easily shown to exist if and only if $\pi_{M}^{N}-F^{N}(H) \geq \pi^{N}\left(w^{H} \alpha \mid 0\right)$. Finally, it is interesting to know that completely inefficient equilibria - that is, equilibria in which $z(H) \neq z(L)=G$ - can never exist, since the existence of such an equilibrium would require $\pi^{N}\left(w^{H} \alpha \mid 1\right) \geq \pi_{M}^{N}-F^{N}(H)$ which would violate assumption (iii). Thus, the multinational equilibrium upon which we focus above is the only equilibrium possibility with $z(L)=G$.

\section{IIIustrations}

\section{Firm-Specific Case}

We consider a market in whlch demand is Iinear, and where there are no flxed costs. Let forelgn demand be represented as $q=\gamma-\beta P$, where $r, \beta>0, q$ is the quantity of goods demanded in the foreign market, and $P$ is the foreign market price. There are $N-1$ foreign firms, and a forelgn firm that produces $q_{f}$ units of output incurs a total cost of $w^{*} a q_{f}$. The single domestic firm incurs a total cost of $w(z) \theta^{H} q_{D}\left(w(z) \theta^{L} q_{D}\right)$ if it makes the location cholce $z$ and has technology $\theta^{H}\left(\theta^{L}\right)$. Assume $w^{*}>w$ and $\alpha>\theta^{H}>\theta^{L}$. 
To find the Cournot quantities for this game of inoomplete information, we perform the following maximizations:

(1)

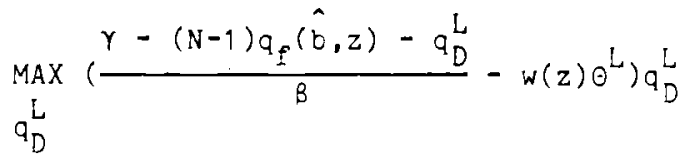

$(2)$

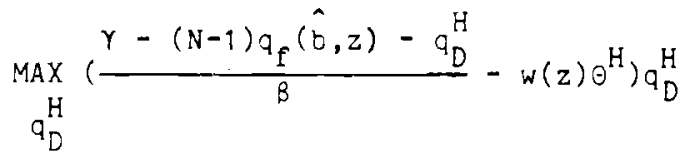

(3)

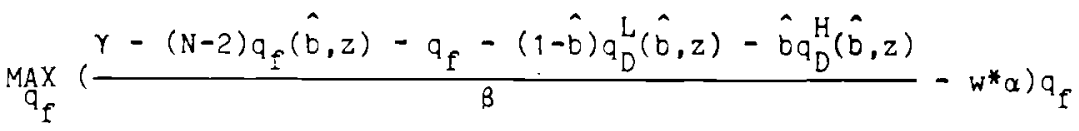

Notice that each firm (and firm type) is on its respective reaction curve. Foreign firms act as it they are playing against an opponent whose optimal quantity is $(1-\hat{b}) q_{D}^{L}(\hat{b}, z)+\hat{b}_{D}^{H}(\hat{b}, z)$.

Letting $\hat{\theta}^{b}=\hat{b} \theta^{H}+(1-\hat{b}) \theta^{L}$, Cournot quantities can be represented as

(4)

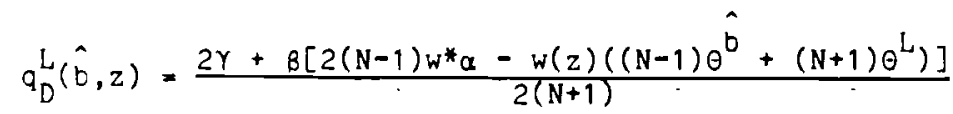

(5)

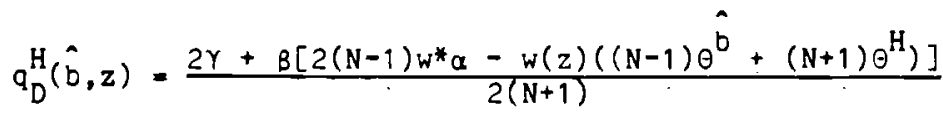

(6)

$$
q_{f}(\hat{b}, z)=\frac{\gamma-B\left[2 w^{*} a-w(z) \theta^{\hat{b}}\right]}{N+1}
$$

Profits are then given by

$$
\Pi^{N}\left(w(z) \theta^{L} \mid \hat{b}\right)=\frac{1}{B}\left(q_{D}^{L}(\hat{b}, z)\right)^{2}
$$


(8) $\quad \Pi^{\mathrm{N}}\left(w(z) \theta^{\mathrm{H}} \mid \hat{b}\right)=\frac{1}{\beta}\left(q_{D}^{\mathrm{H}}(\hat{b}, z)\right)^{2}$

(9) $\quad \Pi^{j}(\hat{b}, z)=\frac{1}{\beta}\left(q_{f}(\hat{b}, z)\right)^{2}, j=1,2, \ldots, N-1$

Provided that equilibrium quantities are positive, it is straightforward to verify that the four assumptions placed on profit functions for the firm-specific case all hold. Note, moreover, that a large value of $y$ ensures positive quantities.

We now employ Theorem 4 to find the conditions under which every undominated equilibrium is a separating multinational equilibrium. The first condition is $\pi^{N}\left(w \theta^{H} \mid 1\right)>\pi^{N}\left(w^{*} \theta^{H} \mid 0\right)$. Calculations give

(10) $\Pi^{N}\left(w \theta^{H} \mid 1\right)=\frac{1}{B}\left\{\frac{2 \gamma+8\left[2(N-1) w^{*} \alpha-2 N w \theta^{H}\right]}{2(N+1)}\right\}^{2}$

(11) $\Pi^{N}\left(w^{*} \theta^{H} \mid 0\right)=\frac{1}{\beta}\left\{\frac{2 \gamma+\beta\left[2(N-1) w^{*} \alpha-(N-1) w^{*} \theta^{L}-w^{*} \theta^{H}(N+1)\right]}{2(N+1)}\right\}^{2}$

Thus, the first condition of Theorem 4 will be met if and only if

$$
\frac{w^{*}}{w}>\left[\frac{2 N}{(N-1) \frac{\theta^{L}}{\theta^{H}}+(N+1)}\right]
$$

For any $\theta^{H}>\theta^{L} \geq 0$, condition (12) will hold if the differential between $w^{*}$ and $w$ is sufpiciently large. Notice that condition (12) is independent of $\gamma$.

The second condition of Theorme 4 is $\pi^{N}\left(w^{*} \theta^{L} \mid 0\right)>\pi^{N}\left(w^{L} \mid \delta_{H}\right)$. Arguing as above, we find that this condition holds if and only if 
(13) $\frac{w^{*}}{W}<\left[\frac{(N-1) \delta_{H}\left(\frac{\theta^{H}}{\theta^{L}}-1\right)+2 N}{2 N}\right]$

Notice that (13) is more likely to hold the smaller is the difference between $W^{*}$ and $W$. Also, observe that (13) too is independent of $Y$, so positive quantities can be assured independent of (12) and (13). Figure 2 illustrates the inequalities (12) and (13). The size (and existence) of the shaded region, which gives values of the foreign and domestic wage for which both inequalities (12) and (13) hold, is determined directly by the relative magnitudes of the slopes of the two lines in figure 2, which are given by the quantities on the right hand side of (12) and (13). While (12) and (13) will be satisfied under a broad range of parameter values, a sufficient condition for the existence of a range of foreign and domestic wage levels which satisfy simultaneously conditions (12) and (13) is that either $\delta_{\mathrm{H}}$ be sufficiently close to one or that $\frac{\theta^{L}}{\theta^{H}}$ be sufficiently close to zero. Hence, the separating multinational equilibrium will be the unique undominated equilibrlum of the flrm-specifio game for a range of foreign and domestic wages if (but not only if) either the efficiency differential between $L$ and $H$ is large enough or the (prior) probability that the domestic firm is inefficient is close enough to one.

We now summarlze with the following theorem.

Theorem 8 When demand is linear and fixed costs are absent, there exists a set of parameter values under which the unique undominated equilibrium of the firm-specific game is the separating multinational equilibrium. A sufficient condition for a range of foreign and domestic 
wages to exist which yield the separating multinational equilibrium uniquely is that either the efficiency differential between $L$ and $H$ is large enough or the prior probability that the domestic firm is inefficient is close enough to one.

\section{Country-Specific Case}

We corsider first a market in which demand is linear, and where there are no fixed costs. Our initial result is negative: under these conditions, $\pi^{N}\left(w_{\alpha}^{L} \mid 1\right)>\pi^{N}\left(w_{\alpha}^{H} \mid 0\right)$ and so an undominated multinational equilibrium does not exist in the country-specific case.

Consider again the simple linear market in which foreign demand is represented as $q=\gamma-\beta P$, where $\gamma, \beta>0, q$ is the quantity of goods demanded in the foreign market, and $P$ is the foreign market price. There are $\mathrm{N}-1$ foreign firms, and a forelgn firm that produces $\mathrm{q}_{\mathrm{f}}$ units of output incurs a total cost of $w^{*} \alpha q_{f}=c^{M} q_{f}$. The single domestic firm incurs a total cost of $C^{M} q_{D}$ if it produces $q_{D}$ unita of output in a foreign plant. If, however, the domestic firm produces $q_{D}$ units of output in a domestic plant, then its total cost is $w^{H} \alpha q_{D}=C^{H} q_{D} \quad\left(w^{L} \alpha q_{D}=C^{L} q_{D}\right)$ if the domestic wage is high (Iow). Assume that $\alpha>0$ and that $w^{H}>w^{*}>w^{L}>0$ so that $C^{H}>C^{M}>C^{L}>0$.

To derive the various profit expressions, we consider a Cournot game of incomplete information in which the domestic firm stays and is thought to face high wages with probatility $\hat{b}$. The resulting cournot quantities, $q_{D}^{L}(\hat{b}), q_{D}^{H}(\hat{b})$, and $q_{f}(\hat{b})$, can then be found by performing the following maximizations: (14) $\operatorname{Max}_{q_{D}^{L}}\left(\frac{\gamma-(N-1) q_{f}(\hat{b})-q_{D}^{L}}{\beta}-C^{L}\right) q_{D}^{L}$ 
(15) $\operatorname{Max}_{q_{D}^{H}}\left(\frac{\gamma-(N-1) q_{f}(\hat{b})-q_{D}^{H}}{\beta}-C^{H}\right) q_{D}^{H}$

(16) $\operatorname{Max}_{\mathrm{q}_{f}}\left(\frac{\left.\gamma-(N-2) \mathrm{q}_{f}(\hat{b})-\mathrm{q}_{f}-\mathrm{q}_{D}^{L}(\hat{b})(1-\hat{b})-q_{D}^{H} \hat{b}\right) \hat{b}}{\beta}-C^{M}\right) q_{f}$

Notice that each firm (and firm type) is on its respective reaction curve. Foreign firms act as if they are playing against an opponent whose optimal quantity is $q_{D}(\hat{b})(\hat{i}-\hat{b})+q_{D}^{H}(\hat{b}) \hat{b}$.

Letting $\hat{C}^{b}=\hat{b} C^{H}+(1-\hat{b}) C^{L}$, it is easy to represent the cournot quantities:

(17) $a_{D}^{L}(\hat{b})=\frac{2 Y+B\left[2(N-1) C^{M}-(N-1) \hat{C}^{\hat{b}}-C^{L}(N+1)\right]}{2(N+1)}$

(18) $\quad q_{D}^{H}(\hat{b})=\frac{2 \gamma+B\left[2(N-1) C^{M}-(N-1) \hat{C}^{\hat{b}}-C^{H}(N+1)\right]}{2(N+1)}$

(19) $a_{f}(\hat{b})=\frac{Y-B\left[2 C^{M}-\hat{C}^{\hat{b}}\right]}{N+1}$

Profits are then given by

(20) $\Pi^{N}\left(w^{L} \alpha \mid \hat{b}\right)=1 / \beta\left(q_{D}^{L}(\hat{b})\right)^{2}$

(21) $\Pi^{N}\left(w_{\alpha}^{H} \mid \hat{b}\right)=1 / B\left(q_{D}^{H}(\hat{b})\right)^{2}$

(22) $\Pi^{j}(\hat{b})=1 / \beta\left(q_{f}(\hat{b})\right)^{2} \quad j=1,2, \ldots, N-1$

Finally, $\Pi_{M}^{j}, j=1,2, \ldots, N$ can easily be computed 
(23) $\Pi_{M}^{j}=1 / B\left[\frac{Y-3 C^{M}}{N+1}\right]^{2} \quad j=1,2, \ldots, N$.

Provided that equilibrium quantities are positive, as they will surely be for large $Y$, it is straightforward to verify that the four assumptions on profit functions made above all hold for this example. The country-specifio theorems of the previous section therefore apply. We are thus left to compare $\Pi^{N}\left(w^{L} \alpha \mid 1\right)$ and $\Pi^{N}\left(w_{\alpha}^{H} \mid 0\right)$. It is straightforward to show that $C^{H}>C^{L}$ is true if and only if $q_{D}^{L}(1)>q_{D}^{H}(0)$. Thus, when demand is linear and fixed costs are absent, a low wage domestic firm thought to face nigh wages produces more than a nigh wage domestic firm thought to face low wages: antual cost effects outweigh perceived cost effects. It is now immediate that $\mathbb{\Pi}^{N}\left(w^{L} \alpha \mid 1\right)>\mathbb{\Pi}^{N}\left(w^{H} \alpha \mid 0\right)$. With fixed costs set to zero by assumption, Theorem 6 then tells us that an undominated multinational equilibrium can never exist. We thus have the following negative result.

Theorem 9: When demand is linear and fixed costs are absent, an undominated multinational equilibrium never exists in the countryspecific case.

Figure 3 fllustrates the result of Theorem 9 for the case of $\mathrm{N}=2$. The slopes of the (linear) forelgn and domestic reaction curves are $-1 / 2$ and -2 , respectively, reflecting the assumption of linear demand. The forelgn reaction curve is labeled MM. The domestic reaction curve when the domestic firm faces high (low) wages is labeled HH (LL). If the domestic firm faces a low wage but is thought by the forelgn firm to face a high wage, then the foreign firm chooses 
$q^{f}(1)$ and the test domestic response is $q_{D}^{L}(1)$. AIternativeiy, if the domestic firm faces a nigh. wage but lo thought by the foreign firm to face a low wage, then the foreign firm scales back its quantity shoice to $q^{f}(0)$, and the best response of the domestic firm is $q_{D}^{H}(0)$. In the general linear demand case, $q_{D}^{L}(1)-Q_{D}^{H}(0)=\frac{B\left(C^{H}-C^{L}\right)}{N+1}>0$. In the case illustrated in Figure 3 with $N=2, Q_{D}^{L}(1)-q_{D}^{H}(0)=\frac{B}{3}\left(C^{H}-C^{L}\right)>0$. Thus, $\pi^{N}\left(w_{\alpha}^{L} \mid 1\right)>\pi^{N}\left(w_{\alpha}^{H} \mid 0\right)$.

Evidentiy, when demand is linear and fixed costs are absent, foreign perceptions of domestic costs are not sufficiently important in the determination of domestic profits to overcome the direct cost effects of locating in the medium wage foreign county when actual domestic wages are low. This rules out the possiblity of undominated multinational equilibria with $z(L)=z(H)=G$ in this case. However, the introduction of plant-specific fixed costs (incurred by the domestic firm only under multinationalization) and of transport costs (incurred by the domestic firm oniy if it exports) allows parameters to be found under which the multinational equilibrium exists and is the unique equiliorium. The role of transport costs is to reduce $\pi^{N}\left(w_{\alpha}^{L} \mid 1\right)$ sufficientiy so that the first condition of Theorem 7 holds $\left(\pi_{M}^{N}-F^{N}(L)>\pi^{N}\left(w^{L} \alpha \mid 1\right)\right)$, while the role of plant-specific fixed costs is to reduce $\Pi_{M^{-}}^{N} F^{N}(H)$ sufficlently so that the second condition of Theorem 7 holds $\left(\pi^{N}\left(w^{H} \alpha \mid 0\right)>\pi_{M}^{N}-F^{N}(H)>\pi^{N}\left(w^{H} \alpha \mid \delta_{H}\right)\right.$.

In particular, in the presence of transport costs $t$ per unit exported from the domestic to the foreign market, the Cournot profits from exporting become 
(24) $\pi\left(w^{L} a \mid \hat{b}\right)=\frac{1}{3}\left[\frac{2 Y+B\left[2(N-1) C^{M}-(N-1)\left(C^{b}+t\right)-(N+1)\left(C^{L}+t\right)\right]}{2(N+1)}\right]^{2}$

(25) $\quad \Pi\left(w^{H} \mid \hat{b}\right)=\frac{1}{8}\left[\frac{2 \gamma+B\left[2(N-1) C^{M}-(N-1)\left(C^{b}+t\right)-(N+1)\left(C^{H}+t\right)\right]}{2[N+1]}\right]^{2}$

With plant-specific fixed costs $F^{\mathrm{N}}(\mathrm{H})\left(F^{\mathrm{N}}(\mathrm{L})\right)$ incurred by the nigh

wage (low wage) domestio firm only if it multinationalizes, profits when multinationalization is chosen are given by

(26) $\pi_{M}^{N}-F^{N}(L)=\frac{1}{3}\left[\frac{Y-B C^{M}}{N+1}\right]^{2}-F^{N}(L)$

(27) $\Pi_{M}^{N}-F^{N}(H)=\frac{1}{B}\left[\frac{\gamma-B C^{M}}{N+1}\right]^{2}-F^{N}(H)$

The conditions of Theorem 7 lead us to calculate

(28) $\Pi_{M}^{N}\left(w^{H} \alpha \mid O\right)=\frac{1}{B}\left[\frac{2 Y+B\left[2(N-1)\left(C^{M}-\frac{C^{L}}{2}-\frac{C^{H}}{2}\right)-2\left(C^{H}+N t\right)\right]}{2(N+1)}\right]^{2}$

(29) $\pi\left(w_{\alpha}^{H} \mid \delta_{H}\right)=\frac{1}{B}\left[\frac{2 Y+B\left[2(N-1)\left(C^{M}-\frac{C^{L}}{2}-\frac{C^{H}}{2}\right)-2\left(C^{H}+N t\right)-2(N-1) \delta_{H}\left(C^{H}-C^{L}\right)\right]}{2(N+1)}\right]^{2}$

(30) $\pi\left(w_{\alpha}^{L} \mid 1\right)=\frac{1}{\beta}\left[\frac{2 \gamma+B\left[2(N-1)\left(C^{M}-\frac{C^{L}}{2}-\frac{C^{H}}{2}\right)-2\left(C^{L}+N t\right)\right]}{2(N+1)}\right]^{2}$

Under tine assumption that $C^{L}$ and $C^{H}$ are symmetric with respect to $c^{M}$, so that

$$
\begin{aligned}
& c^{L}=c^{M}-\psi \quad\left(w^{L}=w^{*}-\frac{\psi}{\alpha}\right) \\
& c^{H}=c^{M}+\psi \quad\left(w^{H}=w^{*}+\frac{\psi}{\alpha}\right)
\end{aligned}
$$


(28) through (30) can be simplified to yield

(31) $\quad \pi\left(w^{H} \alpha \mid 0\right)=\frac{1}{\beta}\left[\frac{\gamma-\beta\left(C^{H}+N t\right)}{N+1}\right]^{2}$

(32) $\pi\left(w_{\alpha}^{H} \mid \delta_{H}\right)=\frac{1}{\beta}\left[\frac{Y-B\left(C^{H}+N t\right)-\beta(N-1) \delta_{H}\left(C^{H}-C^{L}\right)}{N+1}\right]^{2}$

(33) $\pi\left(w^{L} \alpha \mid 1\right)=\frac{1}{B}\left[\frac{\gamma-\beta\left(C^{L}+N t\right)}{N+1}\right]^{2}$

Using (26), (27), (31), (32), and (33), the conditions of Theorem 7 can be evaluated explicitiy. It is stralghtforward to show that, with $F^{N}(L)$ set to zero for simplicity,

(i) $\pi_{M}^{N}>\pi\left(w_{\alpha}^{L} \mid 1\right)$ if and only if $t>\left[\frac{C^{M}-C^{L}}{N}\right]$

(ii) $\pi\left(w_{\alpha}^{H} \mid O\right)>\pi_{M}^{N}-E^{N}(H)$ if and only if $F^{N}(H)>\frac{B^{2}}{(N+1)^{2}}\left(C^{H}-C^{L}\right)\left[\gamma-B\left(C^{H}+N t\right)\right]$

(iii) $\pi_{M}^{N}-F^{N}(H)>\Pi\left(W^{H} \alpha \mid \delta_{H}\right)$ provided $\beta$ is sufficiently small and $\delta_{H}$ is sufficiently close to one.

With $F^{N}(L)$ set to zero and costs symmetric, and with $t, F^{N}(H), B$, and $\delta_{\mathrm{H}}$ chosen to satisfy (i), (ii), and (iii) above, Theorem 7 then implies that in any equiliorium, $z(L)=z(H)=G$; that is, every equilibrium is a multinational equilibrium. $\frac{10}{6}$ we thus have

Theorem 10: In the linear demand model with plant-specific set up costs and transport costs, parameter values exist which make the multinational equilibrium the unique equiliorium. 
IV. Conolusions and Extension

This paper has shown that when firms behave strategically and information about costs is incomplete, multinationals can arise from the desire to transmit cost information to foreign rivals. We have explored the case of country-specific informational asymmetries where the location of production faclities abroad directly informs rival firms of an entrant's production costs, and the case of firm-specific informational asymmetries where the declsion to locate production facilities abroad signals the costs of the entrant. In either case, the firm may te led to multinationalize in the presence of incomplete cost information even though its actual costs of serving the foreign market are higner as a result. Based on our linear demand example, however, it appears that the latter case -- In which location signals firm-specific cost parameters -- ylelds the more plausible multinational equilibrium.

The theory we have explored is clearly only a partial picture, and should be viewed as complementary to other theoretical work on the inultinational enterprise. However, it is consistent with the empirical findings of Swedenborg (1979), that foreign direct investment by Swedish multinationals is more likely in relatively high wage countries, an observation that is inconsistent with existing theories. A slightly modifled model from the firm-speciflo model explored above would also lead to the conclusion that forelgn direct investment is likely to be positively correlated with exports to the host country market: just enough foreign direct investment would be undertaken to signal the firm's efficient technology, and the remalnder of its (now expanded) forelgn market share would be exported from the home plants. Most 
empirical work on the relationship between foreign direct investment and exports finds eitiner no correlation or a positive correlation between the two, something which is again difficult to reconcile with existing theory (see, for example, Bloomstrom, Lipsey, and Kulchycky, 1987). Finaliy, an interesting and important extension would be to add a second period to the game we have analyzed. The domestio firm could then use first-perlod quantity as a signal as well. The interaction of location choice and price/quantity choice as signals of cost is an area we plan to investigate in future work. 


\section{Footnotes}

1) The existing literature on multinationals, both empirical and theoretical, is vast, and we do not attempt to review it here. For a review of this literature see, for example, Caves (1982).

2) The incentive to share cost information with rival firms has been explored recently by Fried (1984), Gal-Or (1986), and Shapiro (1986) under the assumption that cost reports are verifiable. When verification is impossible, direct information exchange is itself impossible. In such cases, observable signals such as price or advertising may be used to transmit cost information, say, to a potential entrant, as in Milgrom and Roberts (1982) and Bagwell and Ramey (forthcoming). The signal we explore here is the location decision.

3/ In both the firm- and country-specific cases, the one-sidedness of the informational asymmetry is not crucial. With risk-neutral firms, nothing would change if the domestic firm were uninformed about the forelgn cost parameter, and made its location decision to $\max 1 \mathrm{~m} 1 z$ e expected profits. Since this adds nothing to the analysis, we abstract from it and concentrate on the case of onesided informational asymmetries.

4f The third option, that of technology licensing, is assumed to be precluded for "transactional" reasons. The possibility of contracting to provide the services of $\mathrm{flrm}-\mathrm{spec} i f i c$ intangible assets to a foreign firm in the country-specific case is similarly precluded. 
5f Thus, the domestic firm chooses its (observed) wage by choosing a plant location and paying the prevailing wage. Wages paid by the domestic firm in excess of the prevailing wage are assumed to be unobservable to foreign firms. This assumption, which is consistent with the notion that foreign firms know the relevant country-specific but not firm-specific information, eliminates the potential for such benavior to serve as a signaling device.

6) We assume that $\theta^{L}<\theta^{H}<\alpha$, so that the domestic firm would never choose to use the commonly known technology $\alpha$.

I' This application is made explicit in the linear demand example used in the following section.

8/ Under our assumptions, it is straightforward to argue that separating equilibria cannot exist in which $z(L) \neq z(H)=G$.

9' of course, it could be the nome country that has the high wage, in which case it would be the inefficient $\left(\theta^{H}\right)$ firm that would multinationalize in the separating equilibrium and the efficient $\left(\theta^{L}\right)$ firm that doesn't, i.e., locates production in the high wage domestic country.

10/ The four assumptions on profit functions listed for the country specific case in section II also need to be satisfied. It is readily shown that a range of parameter values will simultaneously satisfy these four assumptions and the three oriteria listed above. 


\section{References}

Bagwell, Kyle and Garey Ramey, "Advertising and Limit Pricing," Rand Journal of Economics, forthcoming.

Blomstrom, Magnus, Robert E. Lipsey and Knesia Kulchycky, "U.S. and Swedish Direct Investment and Exports," NBER working paper 2390 , September 1987 .

Cayes, Richard E., Multinational Enterprise and Economic Analysis, Cambridge: Cambridge University Press, 1982.

Ethier, Wilfred E., "Foreign Direct Investment and the Multinational Firm," Quarterly Journal of Economies, 1986.

Fried, Dov, "Ineentives for Information Production and Disclosure in $a$ Duopolistic Environment," Quarterly Journal of Economics, May 1984.

Gal-Or, Estiner, "Information Transmission - Cournot and Bertrand Equilioria," Review of Economic Studies, 1986.

Grossman, Sanford and Motty Perry, "Perfect Sequential Equilibria," Journal of Economic Theory $39,1986$.

Kohlberg, Elon and Jean-Francois Mertens, "On the Strategic Stability of Equilibria," Econometrica 54, 1003-1037, 1986.

Kreps, David and Robert Wilson, "Sequertial Equilioria," Econometrica 50,1982 .

Milgrom, Paul and John Roberts, "Limit Pricing and Entry under Incomplete Information: An Equilibrium Analysis," Econometrica 50 , Marcin 1982.

Milgrom, Paul and John Roberts, "Price and Advertising Signals of Product Quality," Journal of Political Economy, XCIV, 796-821 (1986).

Shapiro, Carl, "Exchange of Cost Information in Oligopoly," Review of Economic Studies, 1986.

Swedenborg, Birgitta, The Multinational Operations of Swedish Firms: An Analysis of Determinants and Effects, Stockholm: Almquist and Wiksell International, 1979.

Vernon, Raymond, "International Investments and International Trade in the Product Cycle," Quarterly Journal of Economics, May 1966, 80 , 190-207. 


\section{Eigure 1}

Stage 0

Domestic Firm Privately

Informed of Domestic Costs

stage 1

Stage 2

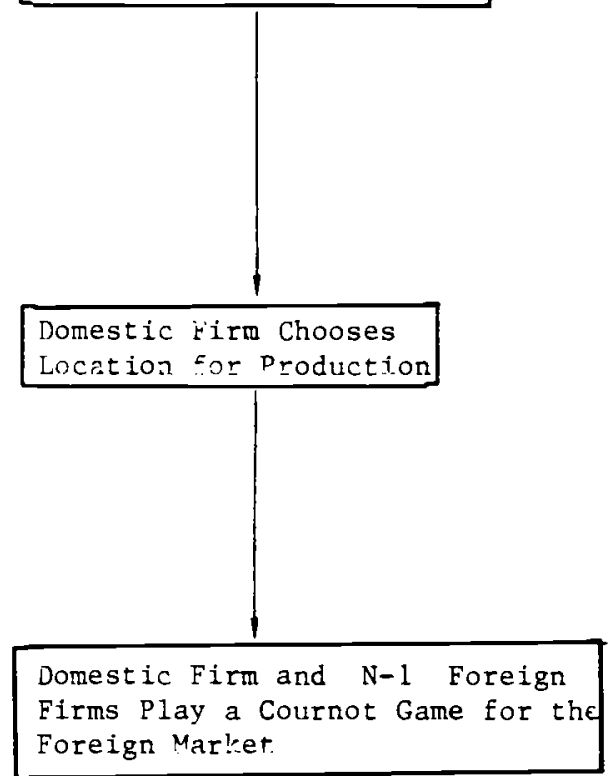


Figure 2

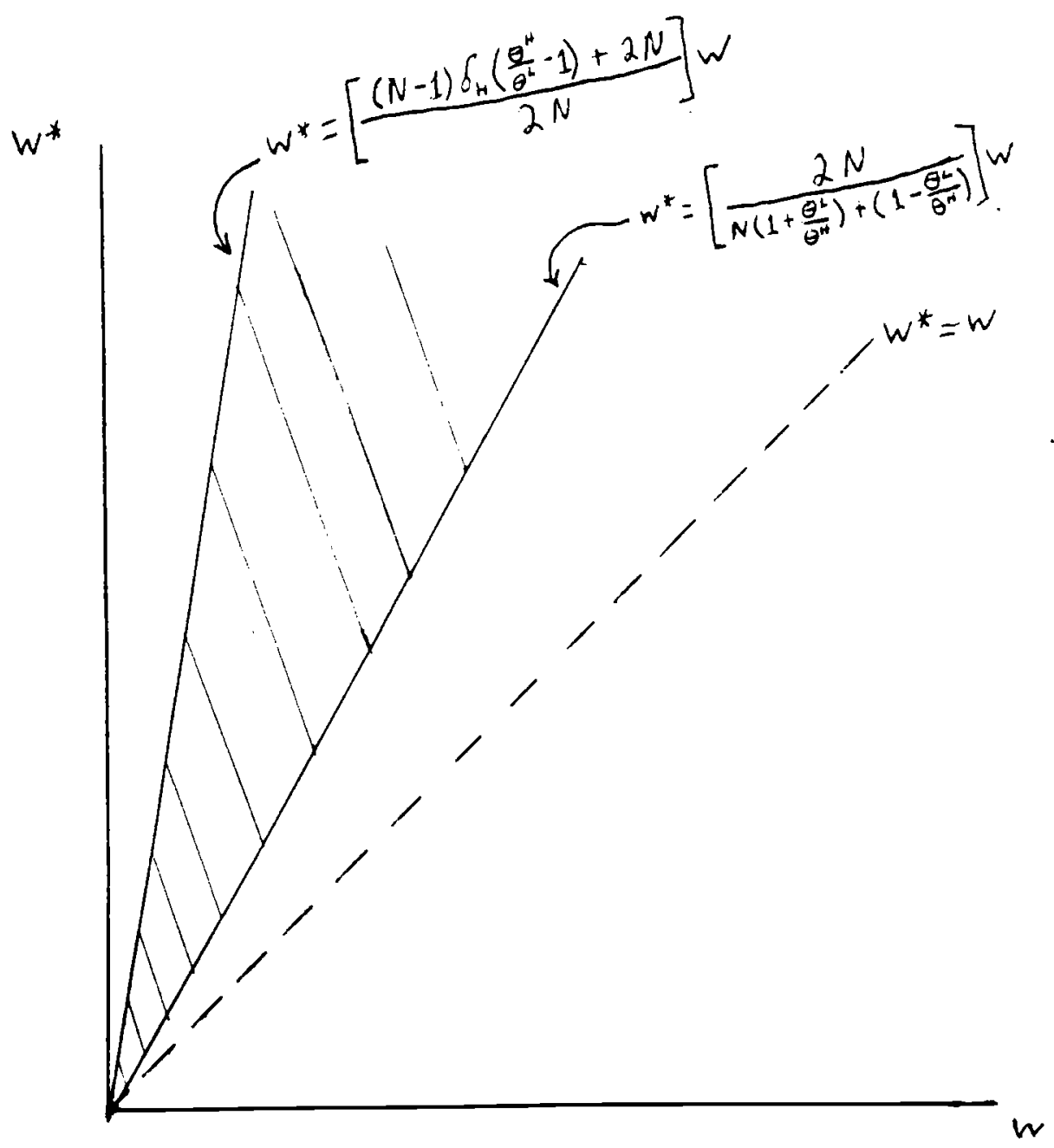


Figure 3

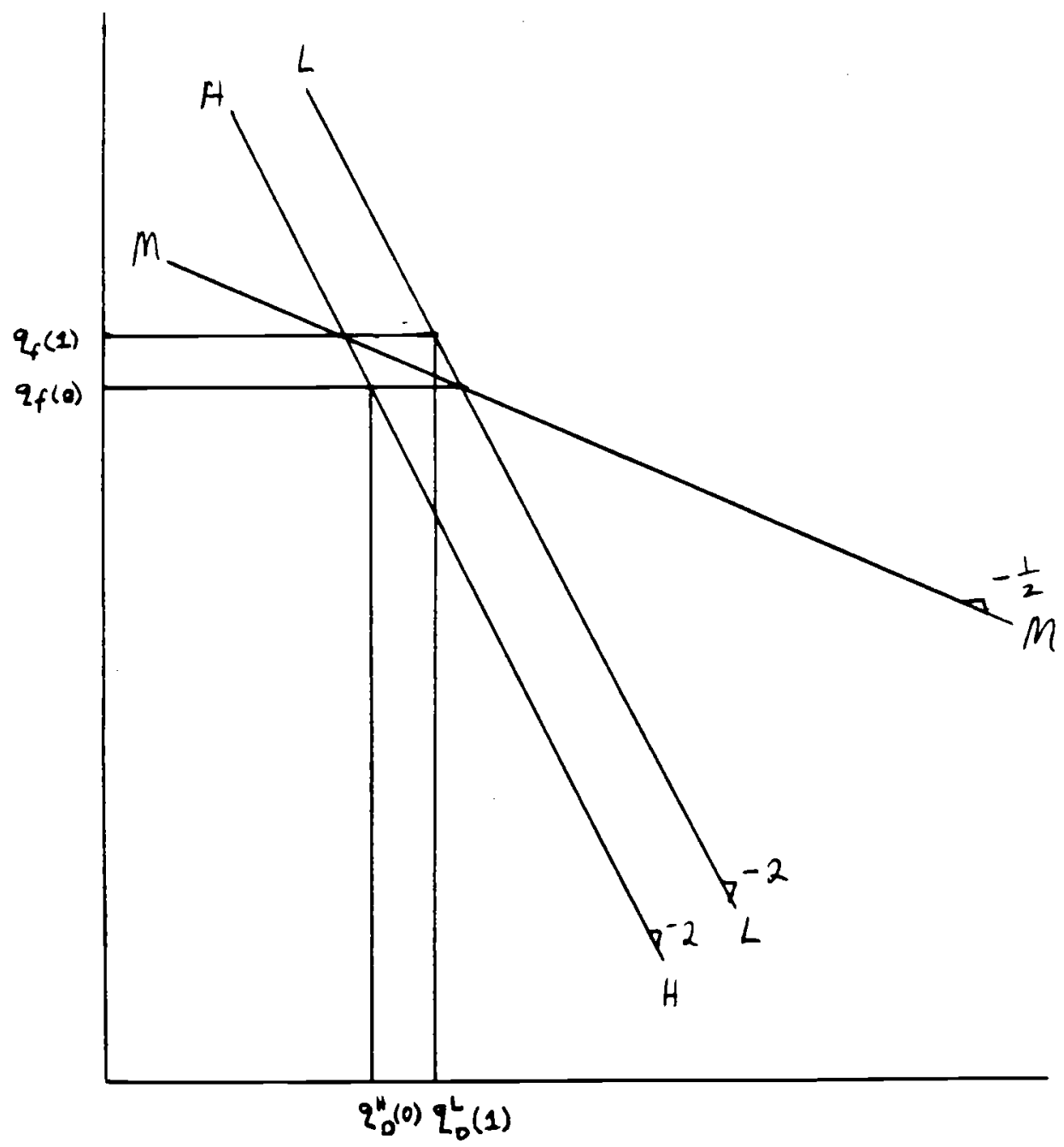

